\title{
Editorial
}

\section{Ivan Giongo}

Assistant Professor, Department of Civil, Environmental and Mechanical Engineering, University of Trento, Trento, Italy

\section{Jason Ingham}

Professor, Department of Civil and Environmental Engineering,

University of Auckland, Auckland, New Zealand

\section{Maurizio Piazza}

Professor, Department of Civil, Environmental and Mechanical Engineering, University of Trento, Trento, Italy
The June issue of Structures and Buildings is an In Focus issue on The Role of Structural Timber in the Earthquake Protection of Masonry Buildings - Part II that completes the themed issue published in May. This month's issue features five stimulating technical papers and it is a pleasure for us to introduce them to you.

In many countries around the World the heritage building stock is largely comprised of unreinforced masonry (URM) buildings with timber roof and floor diaphragms. During earthquakes, these types of structures have proved to be highly vulnerable to lateral loading, with the dynamic response being strongly influenced by timber diaphragm in-plane deformability and the quality of the wall-to diaphragm connections. Understanding the behaviour of timber substructures and their interaction with load-bearing walls is therefore fundamental to the protection of historical buildings in earthquake-prone areas. The characteristics that originally qualified structural timber as the optimal choice for constructing roof and floor diaphragms (i.e. lightweight and high tensile/flexural strength), together with the recent development of new timber based products (e.g. glued-laminated timber, laminated veneer lumber and cross laminated timber), make timber also suitable for dry, reversible and minimally invasive strengthening interventions.

The first three papers in the current issue deal with timber floors, their strengthening, and the influence that timber diaphragms have on the seismic response of masonry buildings. Gubana and Melotto (2021) perform a parametric study on the effectiveness of strengthening timber floor-diaphragms with CLT panels to prevent the out-of-plane collapse of the masonry walls. A simple masonry structure is modelled by the authors using the discrete-element method and is then subjected to ground motion records from past earthquakes. Unreinforced and reinforced floors are simulated via nonlinear springs to reproduce the hysteretic response from previous experimental testing. The parameters investigated by the authors are the structural geometry and the masonry wall thickness. Analysis of the numerical results shows that CLT-based strengthening significantly reduces the out-of-plane displacements of the masonry walls and that the structural performance can match that obtained from using ideal rigid diaphragms.
Trutalli et al. (2021) investigate another timber-based technique available in the literature for the in-plane strengthening and stiffening of existing wood diaphragms. The technique comprises an additional layer of timber boards oriented at $45^{\circ}$ to the joist direction. The authors provide a detailed description of an experimental test campaign where a full-scale $(3.20 \mathrm{~m} \times 2.50 \mathrm{~m})$ floor specimen retrofitted with a diagonal sheathing overlay is subjected to cyclic loading. Based on evidence from the experimental activity, the authors study the effects that the in-plane response of timber floors has on the seismic response of irregular URM buildings. The study, which also addresses stiff concrete-based solutions, was conducted on two case-study buildings modelled using a non-linear macro-element approach. The results presented by the authors indicate that excessively stiff and heavy floor strengthening can be detrimental to the seismic capacity of URM buildings.

Despite the key role of floor-diaphragm behaviour in determining the building seismic response, the reason for intervening on an existing timber diaphragm is often the floor's inability to resist gravity loads. Among the numerous possible strengthening techniques available in the literature, that which sees a thin concrete slab cast on top of the existing floor-decking has proven to be quite popular among practitioners. The retrofit effectiveness is increased by using mechanical fasteners connecting the slab and floor joists, which creates a composite structure. Faggiano et al. (2021) describe the results of a longgoing experimental and numerical study on a particular timber-concrete composite system where the slab-to-joist connection is provided by special steel collars that remove the need for any drilling or cutting of the timber joists. Such collars are tightened to the joists with bolts. The paper provides a wide overview of the technique proposed by the authors, featuring push-out testing of the slab-to-joist connections, testing of full-scale floor specimens in bending, and case-study applications.

With the fourth paper by Zajic (2021) we part from the In Focus topic of "The Role of Structural Timber in Earthquake Protection of Masonry Buildings", even though structural timber remains at the centre of attention, as the paper studies partially-anchored timber-frame walls subjected to lateral loading. The author proposes a simplified procedure for determining the shear capacity of frame walls in multi-storey timber 
buildings. The offset-force method proposed by Zajic is a variation of a lower-bound plastic model known to the literature. In the offset-force method, the height of the application of the resultant horizontal force is kept separate from the wall-height, allowing for a simplified calculation process that does not require iterations. The prediction obtained with the offset-force method is compared with those from well-known methods currently available in the literature, including approaches that have been adopted by codes and guidelines. The theoretical outcomes are then validated on reference test data published by other authors. To validate the proposed method further, Zajic conducted additional testing on 6 frame-wall specimens $(2.61 \mathrm{~m} \times 4.8 \mathrm{~m})$ sheathed with $9 \mathrm{~mm}$ oriented strand board sheets. The comparison between the experimental data and the theoretic values shows that the method proposed by Zajic, while producing conservative predictions of the shear wall capacity as expected from a simplified design method, provides outcomes that are consistent with the robust and refined lower-bound plastic method.

The use of timber material for either retrofit interventions on existing structures or for new building construction is a sustainable choice that generates advantages to the environment in terms of carbon sequestration, greenhouse emission, and energy saving. However, "structural sustainability" is not just a matter of the materials used but concerns the overall building life-cycle. The paper by Grigorian et al. (2021) addresses sustainability from a different perspective, that is the post-earthquake operability of structures where post-event structure realignment and repair play an important role in extending the service life of buildings that have experienced major earthquakes, thus increasing their sustainability. Whilst the attention of academia towards damage control and recentring has grown over last few years, the concept of sustainable earthquake-resistant structures is often neglected by formative paths and codes of practices. The authors present a thorough analysis of concepts and devices aimed at boosting sustainable seismic design. The study dwells on aspects such as adaptive design philosophy, bioinspiration and comparative functional analysis, fail-safe systems, and replaceable energy-dissipating connections (e.g. moment-resisting connections, shear fuses, base-column connections).

We believe that the readers of Structures \& Buildings will find the June issue interesting. Discussions or comments on any of the papers are welcomed and instructions on how to contribute can be found on the papers' last page.

\section{REFERENCES}

Faggiano B, lovane G, Marzo A et al. (2021) Reinforcement of ancient floors by timber-concrete composite systems with collar connector. Proceedings of the Institution of Civil Engineers Structures and Buildings 174(6): 491-503, https://doi.org/10. 1680/jstbu.19.00105.

Grigorian M, Kamizi M and Sedighi S (2021) A basis for developing sustainable earthquake-resisting structures. Proceedings of the Institution of Civil Engineers - Structures and Buildings 174(6): 516-533, https://doi.org/10.1680/jstbu.20.00053.

Gubana A and Melotto M (2021) Discrete-element analysis of floor influence on seismic response of masonry structures. Proceedings of the Institution of Civil Engineers - Structures and Buildings 174(6): 459-472, https://doi.org/10.1680/jstbu.19.00099.

Trutalli D, Marchi L, Scotta R and Pozza L (2021) Seismic capacity of irregular unreinforced masonry buildings with timber floors. Proceedings of the Institution of Civil Engineers - Structures and Buildings 174(6): 473-490, https://doi.org/10.1680/jstbu.19.00115.

Zajic M (2021) A plastic model for partially anchored timber frame walls subjected to shear and bending. Proceedings of the Institution of Civil Engineers - Structures and Buildings 174(6): 504-515, https://doi.org/10.1680/jstbu.19.00032. 